\title{
Dobutamine-Atropine Stress Echocardiography and Clinical Data for Predicting Late Cardiac Events in Patients With Suspected Coronary Artery Disease
}

Don Poldermans, MD, Paolo M. Fioretti, MD, FESC, Eric Boersma, BSE, Jan H. Cornel, MD, Filip Borst, MD, Erik G.J. Vermeulen, MD, Mariarosaria Arnese, MD, Abdou El-Hendy, MD, Jos R.T.C. Roelandt, MD, FACC, Rotterdam, The Netherlands

PURPOSE: To compare the relative value of clinical variables with dobutamine-atropine stress echocardiography to predict cardiac events during long-term follow-up. Dobutamine stress echocardiography is increasingly used for the detection of coronary artery disease, but little is known of its prognostic value.

PATIENTS AND METHODS: A total of 430 patients ( 310 men; mean age 61 years, range 22 to 90 ) were enrolled in the study. Patients were referred for chest pain complaints and were unable to perform an adequate exercise stress test. All patients underwent dobutamine-atropine stress test (incremental dobutamine infusion: 10 to $\mathbf{4 0}$ $\mu \mathrm{g} / \mathrm{kg} /$ minute, continued with atropine 0.25 to 1 $\mathrm{mg}$ intravenously if necessary to achieve $85 \%$ of the age predicted maximal heart rate, without symptoms or signs of ischemia) and clinical cardiac evaluation. Follow-up was $17 \pm 5$ months, with a minimum of 6 months; 3 patients were lost to follow-up. Cardiac events were defined as cardiac death, nonfatal myocardial infarction, and coronary revascularization.

RESULTS: Seventy-nine cardiac events occurred in 76 patients: cardiac death $(\mathrm{n}=11)$, nonfatal myocardial infarction $(n=18)$, and coronary revascularization ( $n=50$ ). By multivariate regression analysis, the prognostic value of the stress test in addition to common clinical variables was assessed. (1) Cardiac death was predicted by age greater than 70 years (odds ratio $5.6,1.5$ to 20 ) or new wall motion abnormalities in a study that is normal at rest (odds ratio $4.1,1.1$ to 15 ). (2) Death or myocardial infarction was predicted by a history of myocardial infarction (odds ratio $4.8,1.8$ to 13 ) or age greater than 70 years (odds ratio $2.3,1.1$ to 5.4), and the stress test outcome provided no

From the Thoraxcenter (DP, FB, EGJV) and Department of Surgery, University Hospital Rotterdam-Dijkzigt and Erasmus University,

Rotterdam, the Netherlands.

Requests for reprints should be addressed to Paolo M. Fioretti, MD,

Thoraxcenter, Ba 300, Academisch Ziekenhuis Rotterdam, Dr

Molewaterplein 403015 GD Rotterdam, The Netherlands.

Manuscript submitted July 23, 1993, and accepted in revised form December 23, 1993. additional information. ( 3 ) If all events were combined, only stress test results were prognostic: new wall motion abnormalities in a study that is normal at rest (odds ratio $3.1,1.9$ to 5.1 ), wall motion abnormalities at rest (wall motion score at rest $\geq 1.12$ ) (odds ratio $2.5,1.4$ to 4.0 ), or any new wall motion abnormalities during stress (odds ratio $2.0,1.4$ to 3.8 ). The positive predictive value of any new wall motion abnormality during stress for all late cardiac events was $25 \%$ (95\% confidence interval [Cl] 19 to 31$)$ with a negative predictive value of $87 \%(95 \% \mathrm{Cl}$ 83 to 91 ).

CONCLUSION: In a large cohort of unselected patients with chest pain syndromes, new wall motion abnormalities induced by dobutamine provide additional information for late cardiac events, independent of clinical variables.

Tn patients with suspected coronary artery disease, Inumerous tests provide prognostic information for late cardiac events in addition to clinical data. These include ambulatory ST segment monitoring, ${ }^{1}$ exercise electrocardiography, ${ }^{2,3}$ radionuclide ventriculography, ${ }^{4}$ thallium perfusion scintigraphy,${ }^{5,6,7}$ and coronary angiography. ${ }^{8}$ Dobutamine-atropine stress combined with echocardiography has been recently proposed for the diagnosis of coronary artery disease by detection of ischemia-induced transient wall motion abnormalities. ${ }^{9-13}$ Dobutamine has both positive inotropic and chronotropic effects on the heart by stimulating $\beta 1, \beta 2$, and $\alpha 1$ adrenoreceptors. The increase of myocardial oxygen demand might induce myocardial ischemia. The test is relatively inexpensive, widely available, independent of physical exercise capacity, safe, ${ }^{14}$ and provides diagnostic information for coronary artery disease. ${ }^{9}$ A few recent studies ${ }^{15-17}$ suggest that the test also has prognostic value, but only one full paper addresses this issue in a study on patients referred for chest pain. Prognostic information for late cardiac events may be valuable for risk stratification and the selection of patients for additional coronary angiography. Clinical variables are often insufficient due to latent coronary artery disease, particularly in patients with limited exercise capacity. Stress electrocardiographic testing provides 


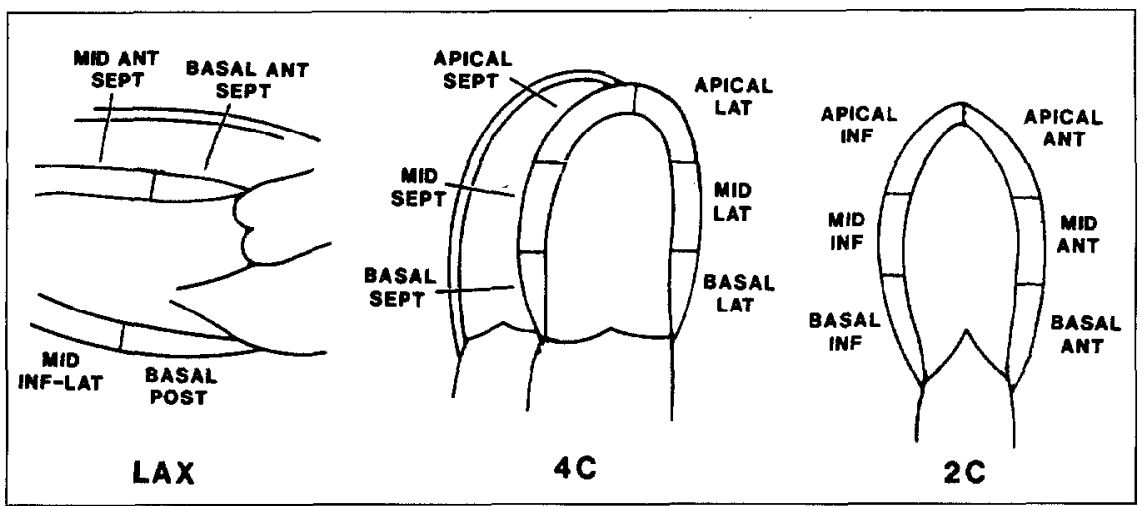

Figure 1. The 14-segment model of the left ventricle. Lax $=$ parasternal long axis; $4 C=$ apical four chamber view; $\mathbf{2 C}=$ apical two chamber view; inf $=$ inferior; sept = septum; lat = lateral; ant $=$ anterior. prognostic information for cardiac events, but it may have limitations for detecting residual ischemia in case of resting electrocardiographic (ECG) abnormalities. ${ }^{4}$ The aim of our study was to assess the relative prognostic value of clinical variables and dobutamine-atropine stress echocardiography in 430 patients referred for chest pain syndromes during 17 months of follow-up.

\section{PATIENTS AND METHODS}

\section{Patient Characteristics}

A total of 430 patients ( 310 men; age range 22 to 90 years, mean 61 years) with known or suspected coronary artery disease were examined, from 1990 until 1992 at the Thoraxcenter. All patients were referred for chest pain complaints (50\% from the outpatient clinic). No patient had a recent infarction (less than 3 months). Clinical data examined were age, sex, previous infarction, angina pectoris, hypertension, smoking, cardiac arrhythmias, history of congestive heart failure, and medication use. A history of previous myocardial infarction was present in 207 patients, and typical angina pectoris in 238 patients. Both angina and previous infarction were present in 97 patients. Anti-anginal medication was continued during the study. A total of 212 patients were using $B$-blockers.

The ECG at rest showed no abnormalities in 209 (49\%) of the cases, a previous myocardial infarction in 192 (45\%), left ventricular hypertrophy in 10 (2.3\%), left bundle branch block in 12 (2.7\%), and right bundle branch block in 7 (1.6\%).

\section{Dobutamine Stress Echocardiography}

The dobutamine-atropine stress echocardiography protocol was approved by the Hospital Ethics Committee and was performed as previously described. ${ }^{13}$ In short, after giving verbal informed consent, the patients underwent a resting two-dimensional precordial echocardiographic examination. Standard apical and parasternal views were recorded on video tape, and a 12-lead ECG was recorded. Dobutamine was then administered intravenously by infusion pump, starting at $10 \mathrm{\mu g} / \mathrm{kg} /$ minute for $3 \mathrm{~min}-$ utes, increasing by $10 \mu \mathrm{g} / \mathrm{kg} /$ minute every 3 minutes to a maximum of $40 \mu \mathrm{g} / \mathrm{kg} /$ minute (stage 4 ), and continued for 6 minutes. In patients not achieving $85 \%$ of their age-predicted maximal heart rate who had no symptoms or signs of ischemia, atropine (starting with $0.25 \mathrm{mg}$ increasing to a maximum of $1 \mathrm{mg}$ ) was given intravenously at the end of stage 4 , while dobutamine was continued. Throughout dobutamine infusion, the ECG was continuously monitored, the 12lead ECG was recorded each minute, and the blood pressure was measured by sphygmomanometry every 3 minutes. The two-dimensional echocardiogram was continuously monitored and recorded on video tape during the final minute of each stage. Quad screen display for side-by-side examination of rest and stress images have become routine during the last 200 studies. Metoprolol was available and used ( 1 to $5 \mathrm{mg}$ intravenously) to reverse the effects of dobutamine or dobutamine-atropine combination if these did not revert spontaneously and quickly. Atropine was used if bradycardia and hypotension occurred. Off-line assessment of echographic images was performed by two experienced investigators without knowledge of the patients' clinical data but with knowledge of the doses of dobutamine and atropine used. When there was disagreement between the two investigators, a third one viewed the images without knowledge of the previous assessments, and a majority decision was achieved. For this semi-quantitative assessment, the left ventricular wall was divided into 14 segments (Figure 1), and each was scored using a 4 point scale: 1 = normal, 2 = hypokinetic, $3=$ akinetic, 4 = dyskinetic. ${ }^{18}$ An increase in score between rest and stress in one or more segments constituted a positive test. All new wall motion abnormalities during stress, group I, were divided into three subgroups: group II $=\mathbf{a}$ new wall motion abnormality in a study that is normal at rest; group III = rest wall motion abnormality with remote ischemic response to stress; and group $\mathrm{IV}=$ worsening of pre-existing wall motion $\mathrm{ab}-$ normality during stress.

Interruption criteria for the test were horizontal or downsloping ST depression of more than $2 \mathrm{~mm}$ at 80 
msec after the J point, ST elevation, serious cardiac arrhythmias, significant chest pain, reduction in systolic blood pressure to more than $40 \mathrm{~mm} \mathrm{Hg}$ from that at rest, a systolic blood pressure of less than $90 \mathrm{~mm}$ $\mathrm{Hg}$, hypertension (systolic blood pressure: greater than or equal to $220 \mathrm{~mm} \mathrm{Hg}$ ), or any side effect regarded as being due to dobutamine.

A new wall motion abnormality was considered as an interruption criteria only if it was severe and extensive. As our experience grew, we were more aggressive in continuing the stress test until target heart rate was reached independent of mild new wall motion abnormalities. We have previously shown excellent inter- and intra-observer reproducibility of interpretation of stress echocardiography of $91 \%$ and $92 \%$, respectively. ${ }^{19}$ In addition, the reproducibility of wall motion abnormalities during dobutamine-atropine stress echocardiography was $100 \%$ in 23 patients who underwent two serial studies on different days. ${ }^{20}$

\section{Follow-Up}

Follow-up data were obtained over $17 \pm 5$ months, with a minimum of 6 months. During follow-up, events defined as cardiac death, nonfatal myocardial infarction, and coronary revascularization (bypass surgery or transluminal angioplasty) were collected. All cardiac events were assessed by physicians unaware of patients former stress test results, by investigation of hospital records, and correspondence with their general physician.

\section{Statistical Analysis}

Univariate analysis for categorial variables (clinical data [age, sex, previous infarction, angina pectoris, hypertension, cardiac arrhythmias, and anti-anginal medication] and stress test results [angina, ST segment changes, new wall motion abnormalities during stress, and rest wall motion abnormalities]) was performed using the chi-square test with Yates correction or Fisher's exact test. Continuous variables were analyzed using Student's $t$-test, when appropriate. KaplanMeier curves were plotted to summarize follow-up data. To compare and visualize the predictive value of rest wall motion abnormalities, we used receiver operator characteristics curves (ROC curves) to find the best cut-off point. In these curves, the sensitivity versus specificity of a test are plotted, in which sensitivity is a fraction of positive classification for all patients who satisfy the endpoint criteria and specificity is the fraction of all negative classifications for all patients who satisfy the non-endpoint criteria. These curves provide a direct comparison of their results over the entire range of measurements. Stepwise logistic regression models were fitted to identify independent clinical predictors of late cardiac events and the additional prognostic value of stress test results. In the

\begin{tabular}{|c|c|}
\hline \multicolumn{2}{|c|}{$\begin{array}{l}\text { Side Effects During Dobutamine-Atropine Stress Test } \\
\text { in } 430 \text { Patients }\end{array}$} \\
\hline \multicolumn{2}{|l|}{ Arrhythmias } \\
\hline Paroxysmal atrial fibrillation & $5(1 \%)$ \\
\hline Nonsustained ventricular tachycardia & $5(1 \%)$ \\
\hline Ventricular fibrillation & $1(0.2 \%)$ \\
\hline Sustained ventricular tactlycardia & $1(0.2 \%)$ \\
\hline Chills & $11(2.6 \%)$ \\
\hline Hypotension $\geq 20$ to $<40 \mathrm{~mm} \mathrm{Hg}$ & $10(2.3 \%)$ \\
\hline Hypotension $\geq 40 \mathrm{~mm} \mathrm{Hg}$ & $2(0.5 \%)$ \\
\hline
\end{tabular}

Hypotension $=$ decrease systolic blood pressure compared to baseline.

case of more than one event in the sante palient, the worst cardiac event was considered for the analysis of the results. The difference in risk was expressed as the odds ratio (OR) with the corresponding 95\% Cls. Differences were considered significant if the null hypothesis could be rejected at the 0.05 probability level.

\section{RESULTS}

Four hundred thirty-two patients were enrolled in the study. In two patients, no adequate echo images could be recorded. Both patients had severe pulmonary disease and were excluded from the study.

In 430 patients, clinical data and stress test results were obtained. In 384 tests (89\%), target heart rate was reached. In 46 (11\%) examinations, the test was prematurely stopped because of severe chest pain in 23 (5\%); ECG changes in 10 (2\%); echographic recorded new wall motion abnormalities in $2(0.5 \%)$; severe hypotension (systolic blood pressure decrease more than $40 \mathrm{~mm} \mathrm{Hg}$ compared with baseline) in $2(0.5 \%)$; cardiac arrhythmias in 6 (1.4\%) (1 ventricular fibrillation, 1 sustained ventricular tachycardia, and 4 paroxysmal atrial fibrillation), and chills in $3(0.7 \%)$. All side effects, though not always causing interruption of the test or occurring during recovery, are shown in Table I. Dobutamine dose used during test was $20 \mu \mathrm{g} / \mathrm{kg} /$ minute in 7 patients, $30 \mu \mathrm{g}$ in 42 patients, and $40 \mu \mathrm{g}$ in 381 patients.

In 176 of 430 examinations, atropine was added in addition to the maximum dose of dobutamine. Atropine addition was more often used in patients on is-blocker medication (OR 4.9, 95\% CI 3.1 to 7.7 in patients receiving versus those not receiving B-blockers). Chest pain during stress occurred in 131 (30\%) patients, and ST segment changes in 154 (36\%). Any new wall motion abnormalities occurred in 182 (42\%) patients (group I). Three subgroups were analyzed. In 149 patients, there was a normal rest echocardiogram and ischemic response to stress (group II); in 31 patients, there were rest wall motion abnormalities with remote ischemic response to stress (group III); and in 39 patients, there was a worsening of pre-existing wall motion abnormalities (group IV). 


\section{TABLE II}

Association by Univariate Analysis of Clinical Data and Stress Test Results With Late Cardiac Events (N = 430)

\begin{tabular}{lccc}
\hline & Cardiac Death & Cardiac Death/Infarction & All Cardiac Events \\
\hline Age $>70$ years & $5.1(1.5-17)$ & $2.3(1.1-5.1)$ & $1.6(0.9-2.8) \mathrm{NS}$ \\
History of intarction & $1.6(0.5-5.5) \mathrm{NS}$ & $5.8(1.9-20)$ & $1.8(0.9-2.4) \mathrm{NS}$ \\
History of angina & $0.6(0.2-2.2) \mathrm{NS}$ & $0.6(0.3-1.3) \mathrm{NS}$ & $1.4(0.7-1.9) \mathrm{NS}$ \\
Diabetes mellitus & $0.5(0.1-1.5) \mathrm{NS}$ & $0.5(0.1-3.5) \mathrm{NS}$ & $0.3(0.1-1.3) \mathrm{NS}$ \\
Anti-anginal medication & $0.5(0.1-1.8) \mathrm{NS}$ & $0.7(0.4-1.6) \mathrm{NS}$ & $1.2(0.7-2.0) \mathrm{NS}$ \\
RWMA & $1.5(0.5-5.0) \mathrm{NS}$ & $2.9(1.3-6.6)$ & $2.7(1.6-4.5)$ \\
Angina during stress & $1.1(0.3-3.9) \mathrm{NS}$ & $1.9(0.9-4.0) \mathrm{NS}$ & $1.5(0.9-2.5) \mathrm{NS}$ \\
NWMA I & $2.4(0.7-8.4) \mathrm{NS}$ & $1.7(0.8-3.6) \mathrm{NS}$ & $2.3(1.4-3.8)$ \\
NWMA II & $3.5(1.1-12)$ & $2.2(1.1-4.7)$ & $3.0(1.8-5.0)$ \\
NWMA III & $1.3(0.2-11) \mathrm{NS}$ & $4.0(1.5-11)$ & $2.3(1.5-11)$ \\
NWMA N & $0.5(0.2-3.1) \mathrm{NS}$ & $0.6(0.4-5.0) \mathrm{NS}$ & $2.1(0.6-6.9) \mathrm{NS}$ \\
\hline
\end{tabular}

Anti-anginal medication $=$ B-blockers and/or nitrates and/or calcium antagonists; RWMA $=$ rest wall motion score index at rest $\geq 1.12 ;$ NWMA I = all new wall motion abnormalities; NWMA $\|=$ normal rest echo, ischemic response to stress; NWMA III = wall motion abnormalities at rest, remote ischemic response to stress; NWMA N = worsening preexisting wall motion abnormalities to stress; NS = not significant.

\section{Side Effects}

Besides chest pain, hypotension and cardiac arrhythmias were the most important side effects of dobutamine-atropine stress test (Table I). There was no correlation between side effects and the addition of atropine (odds ratio $0.7,0.2$ to 1.9 ).

When hypotension was defined as a decrease of systolic blood pressure of more than $20 \mathrm{~mm} \mathrm{Hg}$ compared with baseline, there were 12 incidents. Although most patients were able to continue the test without discomfort, in two patients the test was stopped because of severe and symptomatic hypotension (decrease of systolic blood pressure of more than $40 \mathrm{~mm} \mathrm{Hg}$ ).

The occurrence of hypotension was not related to the dose of dobutamine, atropine addition, or induction of ischemia.

Significant and/or symptomatic cardiac arrhythmias occurred in 12 examinations: 1 patient developed ventricular fibrillation, 1 patient sustained ventricular tachycardia, 5 patients experienced nonsustained ventricular tachycardia, and 5 patients had paroxysmal atrial fibrillation. The test was primarily stopped due to arrhythmias in six examinations. There were no cieaths or myocardial infarctions. All patients who developed atrial fibrillation responded quickly to metoprolol intravenously, and one patient had digitalis as well.

\section{Follow-Up}

Threc patients were lost to follow-up. Seventynine cardiac events occurred during follow-up in 76 patients. Eleven patients experienced cardiac death, and 18 a nonfatal infarction. In 50 patients, a coronary revascularization was performed (bypass surgery or a transluminal angioplasty). Seven patients had a stroke, and there were six noncardiac deaths.
The univariate analysis of clinical data and stress test results to predict cardiac death alone, cardiac death or myocardial infarction, and all cardiac events is presented in Table II. Cardiac death correlated with age greater than 70 years (odds ratio $5.1,1.5$ to 17 ) and new wall motion abnormalities as in group II (odds ratio 3.5, 1.1 to 12); all other variables were not predictive.

Cardiac death or myocardial infarction was related to a history of myocardial infarction (odds ratio 5.8, 1.9 to 20 ), age greater than 70 years (odds ratio 2.3 , 1.1 to 5.1), new wall motion abnormalities as in group III (odds ratio 4.0, 1.5 to 11), rest wall motion abnormalities (wall motion score index at rest $\geq 1.12$ was determined by ROC curves as best cut-off point) (odds ratio $2.9,1.3$ to 6.6 ), or new wall motion abnormalities as in group II (odds ratio 2.2, 1.1 to 4.7).

When cardiac events were combined, they were significantly correlated with new wall motion abnormalities in group II (odds ratio 3.0, 1.8 to 5.0), rest wall motion abnormalities (wall motion score index at rest $\geq 1.12$ ) (odds ratio $2.7,1.6$ to 4.5 ), and new wall motion abnormalities in groups I and III (odds ratio and $2.3,1.4$ to 3.8 and $2.3,1.5$ to 11 , respectively) (Table II). The positive predictive value of any new wall motion response to stress for all late cardiac events was $25 \%$ (95\% CI 19 to 31 ) and a negative predictive value $87 \%$ ( $95 \%$ CI 83 to 91 ).

Multivariate regression analysis was performed on all clinical variables and stress test results. Stress test results were analyzed for their additional prognostic value in addition to common clinical variables. There was a significant correlation between (1) cardiac death and age greater than 70 years (odds ratio 5.6, 1.5 to 20) or new wall motion abnormalities in group II (odds ratio $4.1,1.1$ to 15), (2) cardiac death or myocardial infarction, and a history of a previous myocardial infarction (odds ratio 4.8,1.8 to 13) or age 


\section{TABLE III}

Association by Multivariate Regression Analysis of Clinical Data and Stress Test Results With Late Cardiac Events $(\mathrm{N}=430$ )

\begin{tabular}{lccccccc}
\hline & $\begin{array}{c}\text { Age }>70 \text { yrs } \\
\text { OR }(\mathbf{C l})\end{array}$ & $\begin{array}{c}\text { MI } \\
\text { OR (CI) }\end{array}$ & $\begin{array}{c}\text { RWMA } \\
\text { OR (CI) }\end{array}$ & $\begin{array}{c}\text { NWMA I } \\
\text { OR (CI) }\end{array}$ & $\begin{array}{c}\text { NWMA II } \\
\text { OR (CI) }\end{array}$ & $\begin{array}{c}\text { NWMA III } \\
\text { OR (CI) }\end{array}$ & $\begin{array}{c}\text { NWMA IV } \\
\text { OR (CI) }\end{array}$ \\
\hline Cardiac death & $5.6(1.5-20)$ & NS & NS & NS & $4.1(1.1-15)$ & NS & NS \\
$\begin{array}{l}\text { Cardiac death or } \\
\quad \text { myocardial infarction }\end{array}$ & $2.3(1.1-5.4)$ & $4.8(1.8-13)$ & NS & NS & NS & NS & NS \\
All events & NS & NS & $2.5(1.4-4.0)$ & $2.0(1.4-3.8)$ & $3.1(1.9-5.0)$ & NS & $2.3(1.4-3.9)$ \\
\hline
\end{tabular}

$\mathrm{OR}=$ odds ratio; $\mathrm{Cl}=95 \%$ confidence interval; $\mathrm{Ml}=$ history of previous myocardial infarction; RWMA = rest wall motion $\mathrm{score}$ index $\geq 1.12$; NWMA I = all new all motion abnormalities; NWMA II = normal rest echo, ischemic response to stress; NWMA $\| I=$ wall motion abnormalities at rest remote ischemic response to stress; NWMA $N=$ worsening preexisting wall motion abnormalities to stress; $N S=$ not significant.

\section{TABLE IV}

Events According to the Presence or Absence of a Previous Myocardial Infarction and of the Results of Dobutamine-Atropine Stress Echocardiography

\begin{tabular}{|c|c|c|c|c|c|}
\hline & Death & $\begin{array}{l}\text { Myocardial } \\
\text { Infarction }\end{array}$ & $\begin{array}{c}\text { Coronary } \\
\text { Revasculariation }\end{array}$ & No. of Events & Total Events \\
\hline \multicolumn{6}{|c|}{ No previous MI $(n=223)$} \\
\hline DSE $-(n=147)$ & 0 & 0 & $10(7 \%)$ & $137(93 \%)$ & $10(7 \%)$ \\
\hline $\mathrm{DSE}+(n=76)$ & $3(3.9 \%)$ & $1(1.3 \%)$ & $13(17 \%)$ & $59(76 \%)$ & $17(24 \%)$ \\
\hline \multicolumn{6}{|l|}{ Previous MI $(n=207)$} \\
\hline DSE - $(n=100)$ & $4(4 \%)$ & $8(8 \%)$ & $9(9 \%)$ & $79(78 \%)$ & $21(22 \%)$ \\
\hline $\mathrm{DSE}+(\mathrm{n}=107)$ & $4(3.7 \%)$ & $9(8 \%)$ & $18(17 \%)$ & $76(70 \%)$ & $31(30 \%)$ \\
\hline
\end{tabular}

greater than 70 years (odds ratio 2.3, 1.1 to 5.4), and (3) all cardiac events and new wall motion abnormalities in group II (odds ratio $3.1,1.9$ to 5.0 ), rest wall motion abnormalities (wall motion score index at rest $\geq 1.12$ ) (odds ratio $2.5,1.4$ to 4.0 ), or new wall motion abnormalities in group I (odds ratio 2.0, 1.4 to 3.8)) (Table III).

When patients with and without myocardial infarction were compared (Table IV), there were more cardiac death and myocardial infarctions in the group with a previous myocardial infarction $(P<0.001)$. In 147 patients without a previous myocardial infarction and a negative dobutamine-atropine stress test, no cardiac death or myocardial infarction occurred during follow-up of 17 months. Event-free survival curves for patients with and without new wall motion abnormalities are presented in Figure 2A (endpoints were cardiac death and myocardial infarction) and Figure 2B (all cardiac events). For all cardiac events, there is a significant difference in event-free survival in patients with new wall motion abnormalities.

\section{COMMENTS}

Noninvasive risk stratification in patients with suspected or proven coronary artery disease is of increasing relevance, from one side to the rapid increase of the "therapeutic" modalities and on the other side to economic constraints we face. Pharmacologic stress echocardiography is a very promising tool in this context, since it is widely available and can be ap- plied in almost all patients and is less expensive than other imaging methods, like perfusion scintigraphy. ${ }^{21}$

In this study, we tested the hypothesis that dobutamine-atropine stress echocardiography provides superior information to clinical variables alone, to predict the late clinical outcome in a cohort of 430 patients referred for chest pain at one center.

This is the largest study group so far that we know of with dobutamine-atropine stress echocardiography reported for this purpose. Further since, in our study dobutamine-atropine stress test was considered as a research tool, and the test outcome was not used for clinical management by the attending physicians, a referral bias for coronary arteriography and subsequent revascularization has been avoided.

Our data show that new wall motion abnormalities during dobutamine-atropine stress echocardiography provide additional prognostic information in addition to clinucal variables, when cardiac dealh and all cardiac events were considered. As expected, elderly age (greater than 70 years) was the strongest predictor of cardiac death, while new wall motion abnormalities during stress with a normal rest echocardiogram provided additional prognostic information. When nonfatal infarction was added to death as an endpoint, the predictive power of echo parameters were lost. This is consistent with the lack of predictive value for nonfatal infarction of any stress test ${ }^{22}$ and can be explained by a sudden progression, like a plaque rupture of a moderate lesion that is often undetected by 

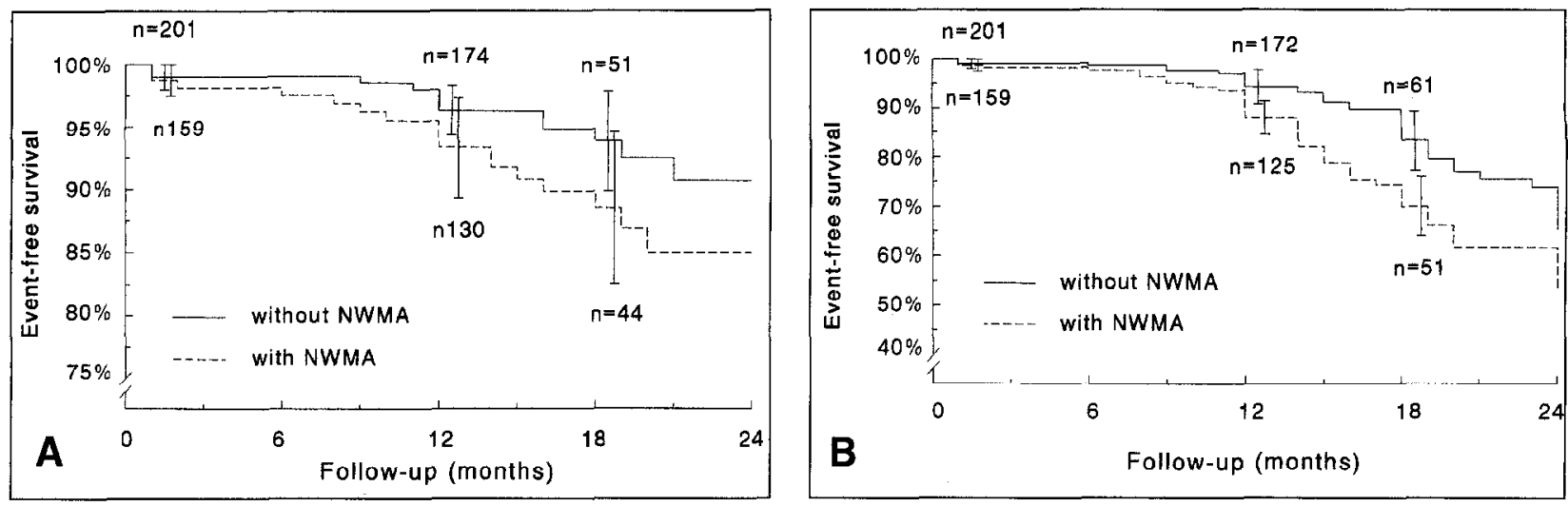

Figure 2. Kaplan-Meier curves for cardiac death and myocardial infarction (A) and all events (B) during follow-up by results of dobutamineatropine stress test (with or without new wall motion abnormalities). Each plot represents the cumulative percentage of patients remaining events free. Vertical lines representing $95 \%$ confidence interval. For all cardiac events, there is a significant difference in event-free survival in patients with new wall motion abnormalities.

the stress test. Common clinical variables such as a previous infarction and elderly age were predictive for cardiac death or nonfatal infarction.

If all cardiac events were combined, only stress test results provided independent information for late events. Stress echocardiographic results were most predictive of subsequent events in patients with normal wall motion at rest and an ischemic response to stress (group II). In contrast, the results were not predictive (group III) or less predictive (group IV) in the presence of abnormal wall motion at rest. This is not surprising, considering that the interpretation of stress echocardiography is most difficult in patients with abnormal wall motions at rest. This is particularly true in patients with akinetic segments becoming dyskinetic during stress. We have recently demonstrated, using perfusion scintigraphy as a reference method, that this pattern is not consistent with ischemia. ${ }^{23}$

Most importantly, echocardiographic results provided additional information beyond clinical data alone. In patients referred for chest pain complaints without a previous myocardial infarction, a negative stress test is associated with a low risk for cardiac death or myocardial infarction.

One study presented as a full paper and two abstracts have addressed the prognostic value of dobutamine stress echocardiography. Unfortunately, the study of Mazeika et $\mathrm{al}^{15}$ is difficult to compare with our study. The population studied consisted of younger paticnts ( $54 \pm 9$ versus $61 \pm 8$ ycars), mostly with typical angina, (78\% versus 55\%) and of limited number (51 versus 430). During follow-up, only one patient had a myocardial infarction, and there were no cardiac deaths. Thus, their endpoints consisted mainly of recurrent angina, and they found a positive predictive value of $78 \%$ and a $95 \%$ CI of 62 to 94 . This is higher than what we found for all cardiac events of $25 \%$ and $95 \%$ CI of 19 to 31 , but this can be due to the very different study group. Also, these authors did not specify to what extent the results of the test were used for subsequent therapeutic interventions, which were considered as endpoints. It is important to underscorc again that in our study the attending physicians were blinded to the results of the test. The negative predictive value was comparable, $78 \%, 95 \%$ CI 62 to 94 in the study by Mazeika et al ${ }^{15}$ versus $87 \%, 95 \%$ CI 83 to 91 in our study.

Two other studies are published in abstract form. The study of Marcovitz et $\mathrm{al}^{16}$ consists of 291 patients with a comparable follow-up of $15 \pm 4$ months and 18 cardiac deaths and 16 myocardial infarctions. Patients with rest wall motion abnormalities (176 versus 291 have a higher incidence of cardiac death compared with patients without resting wall motion abnormalities (16 versus 2 , respectively). In patients with a negative test and no rest wall motion abnormalities (76 of 291), no cardiac death and only 1 myocardial infarction occurred. This is in perfect agreement with our findings. The study of Kamran et al $^{17}$ consists of 207 patients with a shorter follow up of $9 \pm 5.7$ months. 'This study showed by multivariate regression analysis the predictive value of new wall motion abnormalities during stress for cardiac death, although these patients were also assessed for perioperative risk, which might have created a bias.

Dipyridamole echocardiography has also been used for prognostic stratification. The study of Picano et $\mathrm{al}^{24}$ shows similar results to ours with positive predictive value of $36 \%$ and a $95 \%$ CI of 30 to 42 and a negative predictive value of $94 \%$ and a $95 \%$ CI of 91 to 97 for late cardiac events. Dipyridamole thallium scintigraphy has also been used for prognostic evaluation in patients referred for complaints of chest pain. ${ }^{7}$ The predictive value for cardiac death or nonfatal infarction is comparable only if new wall motion abnormalities in group II (with normal rest and the ischemic response to stress) are considered. Positive predictive value in our study is $10 \%$ with a $95 \%$ CI of 
5 to 15 versus $14 \%$ and a $95 \%$ CI of 10 to 18 in the study of Hendel et al. ${ }^{7}$ Both studies show a high negative predictive value of $95 \%$ with a $95 \%$ CI of 92 to 98 versus $96 \%$ with a $95 \%$ CI of 93 to 99 . However, no head-to-head comparison between dipyridamole and dobutamine has been done for risk stratification. Therefore, it is unclear which stress modality should be preferred.

\section{CONCLUSIONS}

In summary, in the present study we found that dobutamine-atropine stress echocardiography applied in patients referred for chest pain complaints identifies a large proportion of patients with an excellent prognosis if the test is normal. In case of stress induced new wall motion abnormalities, the risk for late cardiac events, and especially cardiac death or coronary revascularisation, is increased.

\section{REFERENCES}

1. Raby KE, Goldman L, Cook EF, et al. Long-term prognosis of myocardial ischemia detected by holter monitoring in peripheral vascular disease. Am J Cardiol. 1990;66:1309-1313.

2. Ronnevik PK, von der Lippe G. Prognostic importance of predischarge exercise capacity for long-term mortality and non-fatal myocardial intarction in patients admitted for suspected acute myocardial infarction and treated with metoprolol. Eur Heart J. 1992;13:1468-1472.

3. Fioretti PM, Brower RW, Simoons ML, et al. Prediction of mortality during the first year after acute myocardial infarction from clinical variables and stress test at hospital discharge. Am J Cardiol. 1985;55:1313-1318.

4. Rose EL, Xiu JL, Henley $M$, et al. Prognostic value of noninvasive cardiac tests in the assessment of patients with peripheral vascular. Am J Cardiol. 1993:71:40-44.

5. Brown KA. Prognostic value of thallium-201 myocardial perfusion imaging: a diagnostic tool comes of age. Circulation. 1991:83:363-381.

6. Younis LT, Aguirre F, Byers $S$, et al. Perioperative and long-term prognostic value of intravenous dipyridamole thallium scintigraphy in patients with peripheral vascular disease. Am Heart J. 1990;119:1287-1292.

7. Hendel RC, Layden JJ, Leppo JA. Prognostic value of dipyridamole thallium scintigraphy for evaluation of ischemic heart disease. J Am Coll Cardiol. 990;15:106-109.

8. Hertzer NR, Bcven EG, Young $O$, et al. Coronary artery isease in peripheral vascular patients. A classification of 1000 coronary angiograms and results of surgical management. Ann Surg. 1984;199:223-233.
9. Cohen JL, Greene TO, Ottenweller J, et al. Dobutarnine digital echocardiography for detecting coronary artery disease. Am J Cardiol. 1991;67: 1311-1318.

10. Mannering $D$, Cripps $T$, Leech $G$, et al. The dobutamine stress test as an alternative to exercise testing after acute myocardial infarction. Br Heart $J$. 1988;59:521-526.

11. Marcovitz PA, Armstrong WF. Accuracy of dobutamine stress echocardiography in detecting coronary artery disease. Am J Cardiol. 1992:69:1269-1273.

12. Marwick T, Willemart B, D'Hondt AM, et al. Selection of the optimal nonexercise stress for the evaluation of ischemic regional myocardial dysfunction and malperfusion: comparison of dobutamine and adenosine using echocardiography and $99 \mathrm{mTC}-\mathrm{MIBI}$ single photon emission computed tomography. Circulation. 1993;87:345-354

13. McNeill AJ, Fioretti PM, El-Said EM, et al. Enhanced sensitivity for detection of coronary artery disease by addition of atropine to dobutamine stress echocardiography. Am J Cardiol. 1992;70:41-46.

14. Mertes H, Sawada SG, Ryan T, et al. Symptoms, side effects and complications during dobutamine stress echocardiography: experience in 1043 examinations. Circulation. 1992; 86(Suppl 1):-126. Abstract.

15. Mazeika PK, Nadazdin A, Oakly CM. Prognostic value of dobutamine echocardiography in patients with high pretest likelihood of coronary artery disease. Am J Cardiol. 1993;71:33-39.

16. Marcovitz PA, Bach DS, Shayna VL, Armstrong WF. An abnormal dobutamine stress echocardiogram predicts death and myocardial infarction in the year following study. Circulation. 1992;86(Suppl 1):-1-789. Abstract.

17. Kamran M, Teague S, Finkelhor $R$, et al. Prognosis of patients with an abnormal dobutamine stressecho. J Am Coll Cardiol. 1993;21:384A. Abstract. 18. Edwards WD, Tajik AJ, Seward JB. Standardized nomenclature and anatomic basis for regional tomographic analysis of the heart. Mayo Clin Proc. $1981: 56: 479-497$

19. Pozzoli MMA, Fioretti PM, Salustri A, et al. Exercise echocardiography and technetium-99m MIBI single photon emission computed tomography in the detection of coronary artery disease. Am J Cardiol. 1991;6/:350-35b.

20. Bellotti $P$, Fioretti $P M$, Forster $T$, et al. Reproducibility of dobutamineatropine stress test. Echocardinlogy. 1993;10:93-97.

21. Poldermans D, Fioretti PM, Forster $T$, et al. Dobutamine stress echocardiography for assessment of perioperative cardiac risk in patients undergoing major vascular surgery. Circulation. 1993;87:1506-1512.

22. Steinberg $E H, K o s s J H$, Lee M, et al. Prognostic significance from 10-year follow-up of a quantitatively normal planar exercise thallium test in suspected coronary artery disease. Am J Cardiol. 1993;71:1270-1273.

23. Arnese M, Fioretti PM, Cornel JH, et al. Usefulness of akineses's becoming dyskinesis during high dose dobutamine stress echocardiography as a marker of myocardial ischemia. Am J Cardiol. 1994;73:896-899.

21. Picano E, Severi $S$, Michelassi $C$, et al. Prognostic importance of dipyridamole-echocardiography test in coronary artery disease. Circulation. 1989:80:450-457. 